\title{
Political Ideology and Prioritization of Qualities for Boyfriends-to-be Among Thai Female University Students
}

\author{
Kittisak Jermsittiparsert ${ }^{1} \&$ Waurasit Poothong ${ }^{1}$ \\ ${ }^{1}$ Faculty of Political Science, College of Government, Rangsit University, Thailand \\ Correspondence: Kittisak Jermsittiparsert, Faculty of Political Science, College of Government, Rangsit \\ University, Thailand. E-mail: kittisak.j@rsu.ac.th
}

Received: July 25, 2017 Accepted: September 1, 2017 Online Published: September 6, 2017

doi:10.5539/gjhs.v9n10p127

URL: https://doi.org/10.5539/gjhs.v9n10p127

\begin{abstract}
This research aims to (1) examine the political ideology and prioritization of qualities for men to be chosen as a boyfriend, (2) compare such prioritization among individuals by considering their personal factors, including class years, majors, hometowns, parents' occupations, and household incomes, and (3) test the relationship between the political ideology and such prioritization. The research is conducted by collecting data from 400 female students of a private university in Pathumthani, Thailand who registered in the final semester of the 2016 academic year. The data are collected via questionnaires, and statistically analyzed by finding the frequencies, percentages, means, and standard deviations as well as by adopting the methods of one-way analysis of variance (ANOVA), Tukey's Pairwise Comparison Test, and Pearson's correlation coefficient analysis, with the statistical significance set at the 5 -percent level. The results show that overall the sample's political ideology leans slightly towards liberalism, and the sample gives a moderate priority to the qualities of men to be chosen as a boyfriend. The quality to which the sample gives the top priority is the personal characters of the men. It is also found that the five personal factors also affect the prioritization of qualities for men to be chosen as a boyfriend, and that the political ideology and the prioritization of qualities for the boyfriend-to-be are only weakly related.
\end{abstract}

Keywords: political ideology, liberalism, conservatism, university students, boyfriend

\section{Introduction}

A French thinker "Antoine-Louis Destutt de Tracy" initiated the use of the term "ideology" as a subject of human thoughts that can be studied and researched empirically. If it is believed that human thoughts come from human's physique, and if research can be done, and rules established, with regards to human's physique, then rules, origins, and growths of human thoughts can also be done. The study of ideology, therefore, presents an attempt to find the governing rules of human thoughts. When put in comparison with Isaac Newton's discovery of gravity, which was key to unlocking the mystery of the universe, the task of studying human thoughts may be considered comparable to being Newton in the science of thoughts (Wanthana, 2008: 9-10).

However, the studies in sociology and political science in the 1950s to the 1960s by "End-of-Ideology" theorists, such as Daniel Bell (1960), Seymour Lipset (1960), Philip Converse (1964), Edward Shils (1968), and Raymond Aron (1968), result in an observation on ideologies that the ideological range from liberalism (left) and conservatism (right) (Figure 1) lacks (1) cognitive structure, (2) motivational potency, (3) substantive philosophical differences, and (4) characteristic psychological profiles (Jost, 2006a: 76), which has led to questions at least four decades later whether or not the polarization of ideologies this way remains meaningful or useful (Jost, 2006b: 651).

Questions and attempts to make small arguments regarding the role of ideology on daily life occasionally appear in the article "Ideology: A Definitional Analysis" (1997) by John Gerring, a professor of political science at Boston University. A pioneer work in the field is done by John Jost, a professor of psychology and politics at New York University, and his team by emphasizing the psychological hypothesis that the differences in psychological drives and tendencies are rooted in the ideological differences between the left and the right (Jost, Glaser, Kruglanski and Sulloway, 2003: 339). Later, Jost publishes the article "The End of End of Ideology" (2006b), where he made a counter-argument to the hypothesis earlier posited by the End of Ideology's theorists that such hypothesis may be self-defensible in the 1950s within the context that it was developed but not anymore in the current political circumstance. Numerous studies and surveys, particularly those done by psychologists, point out that not only are 
ideologies present everywhere, but they also play an important role in people's lives.

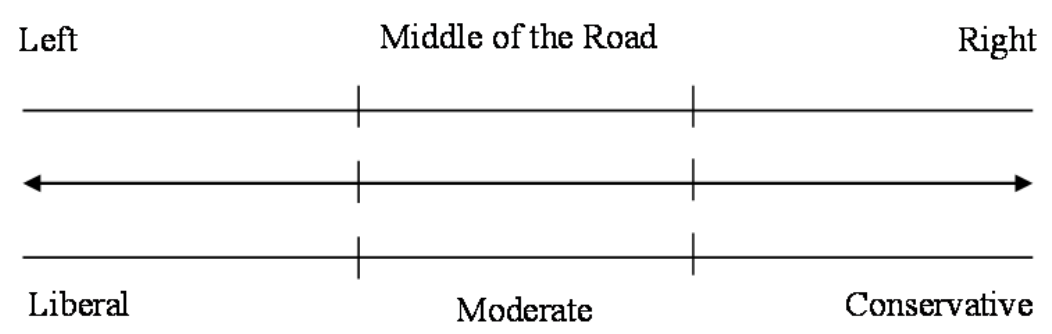

Figure 1. Political spectrum

Reviews of claims made by the End of Ideology's theory (Jost, 2006a), the findings of behavioral differences between the liberals and the conservatives (Carney, Jost, Gosling, \& Potter, 2008; Klofstad, McDermott, \& Hatemi, 2012), the explanations of how one's ideologies come about, or why one becomes left or right (Young, 2009), the demonstration that the moral foundation of the two ideologies may differ (Graham, Haidt, \& Nosek, 2009), and the empirical evidence based on the behavioral and the neurological data (Jost \& Amodio, 2012) all support de Tracy's comments on the importance of ideological studies, where ideologies are believed to dictate human's mind and empirically testable.

Choosing a man to become a boyfriend is a social behavior in daily life that has gained much interest and been frequently and widely brought up in Thailand (Pantip, 2013, 2014, 2016; Boy, 2016). Examples are such as the branding of "gold-digging women" (Thai folk song by Chaitong Songpol) as well as the idea that men have to be "handsome, rich, and well-educated" (Dara Daily, 2017) or "smart, romantic, gentle, musically-talented, athletic" (Wongnai, 2015). This leads to a research question, in the same manner as "fear of wife" has been addressed (Jermsittiparset \& Theansri, 2017), of whether in fact Thai women gives any priorities to the quality of men they choose to become their boyfriend, and if so, what qualities are prioritized at what level. It may also be asked further whether these priorities are different depending on each woman's backgrounds, and finally, whether there is a relationship between the woman's political ideology and such priorities.

\subsection{Research Objectives}

This research intends to (1) study the political ideologies and the prioritization of quality of men to be chosen as a boyfriend, (2) compare such prioritization among women with different personal factors, and (3) test the relationship between the political ideology and the level of prioritization both for overall quality and for each aspect of the qualities.

\subsection{Conceptual Framework}

Independent variables

\begin{tabular}{|ll|}
\hline Personal factors & \\
\hline - Class year & - Major \\
- Hometown & - Parent's occupation \\
- Household income & \\
\hline
\end{tabular}

Political ideology (Note 1)

\section{Dependent variables}

\begin{tabular}{|ll|}
\hline $\begin{array}{l}\text { Prioritization on the quality of men } \\
\text { to be chosen as a boyfriend }\end{array}$ \\
\hline - Family background \\
- Financial status & - Age \\
- Physical appearance & - Occupation \\
- Intellect & - Character \\
- Other benefits & - Celebrity \\
\hline
\end{tabular}

\section{Research Methodology}

\subsection{Population and Sample}

The researcher specifies the population of this research as the female students of a private university in Pathumthani, Thailand, which has maintained the student status and registered for the last semester of the 2016 academic year (January-May 2017). Computing the sample size without knowing the population size with 
Cochran's formula (1977) at the 95-percent confidence level and the 5-percent significance level results in the sample size of 400 people.

\subsection{Data Collection}

A questionnaire is used as a tool to collect data, and it is composed of three sections, including (1) personal factors, such as class year, major, parent's occupation, and household income, (2) political ideology, which is constructed according to Somkiat Wanthana's explanation of "general characteristics of liberalism" (Wanthana, 2008: 24-28, 48-57), including individualism, freedom, reason, equality, toleration, consent, constitutionalism, and of "basic foundation of conservatism", including tradition, pragmatism, human imperfection, organicism, hierarchy, authority, and property, and (3) prioritization of quality of men to be chosen as a boyfriend, including family background, age, financial status, occupation, physical appearance, personal character, intellect, celebrity, other benefits, and sexual skills. The data are collected from April to May 2017.

\subsection{Data Analysis}

The researcher analyzes the data statistically, by finding the frequencies, percentages, means, and standard deviations, and by adopting the methods of one-way analysis of variance (ANOVA), Tukey's pairwise comparison test, and Pearson's correlation coefficients, with the statistical significance set at the 5-percent level and the interpretation of correlation coefficients by Hinkle, Wiersma, and Jurs' criteria (2003).

\section{Research Results}

\subsection{Personal Factors}

Most subjects in the sample study in the third year (34.8 percent) in engineering and technology majors (29.8 percent), specify Bangkok and its vicinities as their hometown ( 24.2 percent) and doing own business as their parent's occupation (39.5 percent), and have the household income between 20,001-40,000 baht per month (31.0 percent).

Table 1. Personal factors

\begin{tabular}{|c|c|c|c|c|c|}
\hline Class year & $\mathbf{N}$ & pet & Class year & $\mathbf{N}$ & pet \\
\hline First year & 60 & 15.0 & Second year & 101 & 25.2 \\
\hline Third year & 139 & 34.8 & Fourth year & 100 & 25.0 \\
\hline Major & $\mathbf{N}$ & pet & Major & $\mathbf{N}$ & pet \\
\hline Science-Health & 114 & 28.5 & Engineering-Technology & 119 & 29.8 \\
\hline Humanities-Social science & 76 & 19.0 & Economics-Business & 89 & 22.2 \\
\hline Arts-Design & 2 & 0.5 & & & \\
\hline Hometown & $\mathbf{N}$ & pct & Hometown & $\mathbf{N}$ & pet \\
\hline Bangkok/Vicinities & 97 & 24.2 & Northern region & 81 & 20.2 \\
\hline Northeastern region & 92 & 23.0 & Central region & 88 & 22.0 \\
\hline Southern region & 42 & 10.5 & & & \\
\hline Parent's occupation & $\mathbf{N}$ & pet & Parent's occupation & $\mathbf{N}$ & pet \\
\hline Public servants & 83 & 20.8 & Private employees & 56 & 14.0 \\
\hline Business owners & 158 & 39.5 & Farmers & 53 & 13.2 \\
\hline General contractors & 38 & 9.5 & Others & 12 & 3.0 \\
\hline Household income & $\mathbf{N}$ & pet & Household income & $\mathbf{N}$ & pet \\
\hline$\leq 20,000$ baht & 40 & 10.0 & $20,001-40,000$ baht & 124 & 31.0 \\
\hline $40,001-60,000$ baht & 115 & 28.8 & $60,001-80,000$ baht & 72 & 18.0 \\
\hline $80,001-100,000$ baht & 25 & 6.2 & $\geq 100,001 \mathrm{baht}$ & 24 & 6.0 \\
\hline
\end{tabular}




\subsection{Political Ideologies}

The political ideologies among the subjects in the sample range from highly liberal (average $=4.26$ out of 5) to highly conservative (average $=4.22$ out of 5 ), whereby equality (average $=4.43$ out of 5 ) and organicism (average $=4.30$ out of 5) are the most prominent traits of liberalism and conservatism respectively. Overall, the political ideology of the sample leans slightly towards liberalism (average $=0.04$ ).

Table 2. Political ideologies

\begin{tabular}{llllll}
\hline Liberalism & Mean & S.D. & Conservatism & Mean & S.D. \\
\hline Individualism & 4.13 & 0.59 & Tradition & 4.24 & 0.53 \\
Freedom & 4.29 & 0.51 & Pragmatism & 4.22 & 0.59 \\
Reason & 4.11 & 0.55 & Human imperfection & 4.23 & 0.60 \\
Equality & 4.43 & 0.62 & Organicism & 4.30 & 0.56 \\
Toleration & 4.39 & 0.51 & Hierarchy & 4.17 & 0.63 \\
Consent & 4.22 & 0.54 & Authority & 4.25 & 0.57 \\
Constitutionalism & 4.24 & 0.54 & Property & 4.10 & 0.56 \\
\hline Total & $\mathbf{4 . 2 6}$ & $\mathbf{0 . 3 2}$ & Total & $\mathbf{4 . 2 2}$ & $\mathbf{0 . 3 6}$ \\
\hline
\end{tabular}

\subsection{Prioritization of Quality of Men to be Chosen as a Boyfriend}

The sample moderately rates the prioritization of men to be chosen as a boyfriend (mean $=5.31$ out of 10 ). Personal character is the quality most highly prioritized by the sample (mean $=6.69$ out of 10). Intellect is the second highly prioritized quality (mean $=5.70$ out of 10 ). Having other benefits is the quality given the least priority, with the score also being at the moderate level (4.79 out of 10).

Table 3. Prioritization of quality of men to be chosen as a boyfriend

\begin{tabular}{llllll}
\hline Quality & Mean & S.D. & Quality & Mean & S.D. \\
\hline Family background & 4.95 & 2.33 & Age & 5.44 & 2.42 \\
Financial status & 5.40 & 2.40 & Occupation & 4.94 & 2.79 \\
Physical appearance & 5.34 & 2.20 & Personal character & 6.69 & 2.39 \\
Intellect & 5.70 & 2.60 & Social celebrity & 4.83 & 2.67 \\
Other benefits & 4.79 & 3.08 & Sexual skill & 5.01 & 2.77 \\
\hline Total & & & $\mathbf{5 . 3 1}$ & $\mathbf{1 . 7 4}$ \\
\hline
\end{tabular}

\subsection{Comparison of Prioritization Given to the Quality of Men to be Chosen as a Boyfriend}

The comparison of priority levels given to the quality of men to be chosen as a boyfriend among female students categorized by class years, by way of one-way analysis of variance, finds that female students of different class years give different priorities with regards to such quality (Table 4). When Tukey's pairwise comparison test is employed, it is found that the third-year students (mean $=5.06$ out of 10 ) give a lower priority to the quality of men to be chosen as a boyfriend than do the fourth-year students (mean $=5.78$ out of 10) (Table 5). 
Table 4. Comparison of prioritization given to the quality of men to be chosen as a boyfriend categorized by class years

\begin{tabular}{llllll}
\hline Class years & $\mathbf{N}$ & Mean & S.D. & F & p-value \\
\hline First-year & 60 & 5.26 & 1.67 & 3.584 & $.014^{*}$ \\
Second-year & 101 & 5.21 & 1.45 & & \\
Third-year & 139 & 5.06 & 1.95 & & \\
Fourth-year & 100 & 5.78 & 1.69 & & \\
\hline
\end{tabular}

Table 5. Pairwise comparison for prioritization given to the quality of men to be chosen as a boyfriend categorized by class years

\begin{tabular}{llllll}
\hline Class years & Mean & $\mathbf{1}$ & $\mathbf{2}$ & $\mathbf{3}$ & $\mathbf{4}$ \\
\hline First-year & 5.26 & - & .998 & .876 & .253 \\
Second-year & 5.21 & - & - & .911 & .089 \\
Third-year & 5.06 & - & - & - & $.008^{* *}$ \\
Fourth-year & 5.78 & - & - & - & - \\
\hline
\end{tabular}

Likewise, the comparison of prioritization given to the quality of men to be chosen as a boyfriend among female students categorized by majors, by way of one-way analysis of variance, finds that female students of different majors give different priorities to the quality of men to be chosen as a boyfriend (Table 6). Tukey's pairwise comparison test finds that the female students majoring in economics or business (mean $=4.84$ ) give a lower priority to the quality of men to be chosen as a boyfriend than do those majoring in the fields of science and health $($ mean $=5.53)$ or engineering and technology $($ mean $=5.56)($ Table 7$)$.

Table 6. Comparison of prioritization given to the quality of men to be chosen as a boyfriend categorized by majors

\begin{tabular}{llllll}
\hline Major & $\mathbf{N}$ & Mean & S.D. & F & p-value \\
\hline Science-health & 114 & 5.53 & 1.69 & 3.047 & $.017^{*}$ \\
Engineering-technology & 119 & 5.56 & 1.44 & & \\
Humanities-social science & 76 & 5.12 & 1.88 & & \\
Economics-business & 89 & 4.84 & 1.98 & & \\
Arts-design & 2 & 5.95 & 1.20 & & \\
\hline
\end{tabular}

Table 7. Pairwise comparison of prioritization given to the quality of men to be chosen as a boyfriend categorized by majors

\begin{tabular}{lllllll}
\hline Major & Mean & $\mathbf{1}$ & $\mathbf{2}$ & $\mathbf{3}$ & $\mathbf{4}$ & $\mathbf{5}$ \\
\hline Science-health & 5.53 & - & 1.000 & .495 & $.040^{*}$ & .997 \\
Engineering-technology & 5.56 & - & - & .405 & $.025^{*}$ & .998 \\
Humanities-social science & 5.12 & - & - & - & .839 & .962 \\
Economics-business & 4.84 & - & - & - & - & .897 \\
Arts-design & 5.95 & - & - & - & - & - \\
\hline
\end{tabular}

The comparison of prioritization of the quality of men to be chosen as a boyfriend among female students categorized by hometowns, by way of one-way analysis of variance, finds that the female students from different hometowns give different priorities to the quality of men to be chosen as a boyfriend (Table 8). Moreover, by way of Tukey's pairwise comparison test, it is found that the female students coming from the Northern region (mean = 5.86 out of 10) gives a higher priority to the quality of men to be chosen as a boyfriend than do the female students 
from Bangkok and its vicinities (mean $=4.97$ out of 10$)$ and those from the Southern region (mean $=4.63$ out of 10). It is also found that the female students from the Northeastern region also gives a higher priority to the quality of men to be chosen as a boyfriend than do those from the Southern region (mean $=4.63$ out of 10) (Table 9).

Table 8 . Comparison of prioritization given to the quality of men to be chosen as a boyfriend categorized by hometowns

\begin{tabular}{llllll}
\hline Hometown & N & Mean & S.D. & F & p-value \\
\hline Bangkok and vicinities & 97 & 4.97 & 1.87 & 5.026 & $.001^{* *}$ \\
Northern region & 81 & 5.86 & 1.29 & & \\
Northeastern region & 92 & 5.52 & 1.84 & & \\
Central region & 88 & 5.29 & 1.68 & & \\
Southern region & 42 & 4.63 & 1.79 & & \\
\hline
\end{tabular}

Table 9. Pairwise comparison of prioritization given to the quality of men to be chosen as a boyfriend categorized by hometowns

\begin{tabular}{lllllll}
\hline Hometown & Mean & $\mathbf{1}$ & $\mathbf{2}$ & $\mathbf{3}$ & $\mathbf{4}$ & $\mathbf{5}$ \\
\hline Bangkok and vicinities & 4.97 & - & $.005^{* *}$ & .179 & .695 & .830 \\
Northern region & 5.86 & - & - & .685 & .204 & $.002^{* *}$ \\
Northeastern region & 5.52 & - & - & - & .906 & $.046^{*}$ \\
Central region & 5.29 & - & - & - & - & .243 \\
Southern region & 4.63 & - & - & - & - & - \\
\hline
\end{tabular}

The comparison of the prioritization of the quality of men to be chosen as a boyfriend of female students categorized by parent's occupation by way of one-way analysis of variance shows that the female students differing in their parent's occupation differently prioritize the quality of men to be chosen as a boyfriend (Table 10). By Tukey's pairwise comparison test, it is further found that the female students whose parent's occupation is farming (mean $=6.05$ out of 10 ) gives a higher priority to the quality of men to be chosen as a boyfriend than do the female students whose parent's occupation is private employee (mean $=5.06$ out of 10 ) or public servants or officers of state enterprises (mean $=4.94$ out of 10$)($ Table 11$)$.

Table 10. Comparison of prioritization of the quality of men to be chosen as a boyfriend categorized by parent's occupation

\begin{tabular}{llllll}
\hline Parent's occupation & N & Mean & S.D. & F & p-value \\
\hline Public servants & 83 & 4.94 & 1.96 & 2.991 & $.012^{*}$ \\
Private employees & 56 & 5.06 & 1.69 & & \\
Business owners & 158 & 5.33 & 1.72 & & \\
Farmers & 53 & 6.05 & 1.27 & \\
General contractors & 38 & 5.32 & 1.87 & \\
Others & 12 & 5.53 & 1.42 & & \\
\hline
\end{tabular}


Table 11. Pairwise comparison of prioritization of the quality of men to be chosen as a boyfriend categorized by parent's occupation

\begin{tabular}{llllllll}
\hline Parent's occupation & Mean & $\mathbf{1}$ & $\mathbf{2}$ & $\mathbf{3}$ & $\mathbf{4}$ & $\mathbf{5}$ & $\mathbf{6}$ \\
\hline Public servants & 4.94 & - & .999 & .550 & $.004^{* *}$ & .869 & .873 \\
Private employees & 5.06 & - & - & .914 & $.035^{*}$ & .979 & .954 \\
Business owners & 5.33 & - & - & - & .095 & 1.000 & .999 \\
Farmers & 6.05 & - & - & - & - & .353 & .939 \\
General contractors & 5.32 & - & - & - & - & - & .999 \\
Others & 5.53 & - & - & - & - & - & - \\
\hline
\end{tabular}

Finally, the comparison of the quality of men to be chosen as a boyfriend among female students categorized by household income, by way of one-way analysis of variance, finds that the female students with different household incomes differently prioritize the quality of men to be chosen as a boyfriend (Table 12). When Tukey's pairwise comparison is adopted, it is found that the female students with household income no more than 20,000 baht per month (mean $=5.99$ out of 10 ) give a higher priority to the quality of men to be chosen as a boyfriend than do those with household income from 40,001 to 60,000 baht per month (mean $=5.04$ out of 10) (Table 13).

Table 12. Comparison of prioritization of men to be chosen as a boyfriend categorized by household income

\begin{tabular}{llllll}
\hline Household income & N & Mean & S.D. & F & p-value \\
\hline$\leq 20,000$ baht & 40 & 5.99 & 1.39 & 2.776 & $.018^{*}$ \\
$20,001-40,000$ baht & 124 & 5.10 & 1.72 & & \\
$40,001-60,000$ baht & 115 & 5.04 & 1.81 & & \\
$60,001-80,000$ baht & 72 & 5.66 & 1.72 & & \\
$80,001-100,000$ baht & 25 & 5.34 & 1.68 & & \\
$\geq 100,000$ baht & 24 & 5.45 & 1.89 & & \\
\hline
\end{tabular}

Table 13. Pairwise comparison of prioritization of men to be chosen as a boyfriend categorized by household income

\begin{tabular}{llllllll}
\hline Household income & Mean & $\mathbf{1}$ & $\mathbf{2}$ & $\mathbf{3}$ & $\mathbf{4}$ & $\mathbf{5}$ & $\mathbf{6}$ \\
\hline$\leq 20,000$ baht & 5.99 & - & .057 & $.034^{*}$ & .928 & .688 & .838 \\
$20,001-40,000$ baht & 5.10 & - & - & 1.000 & .257 & .989 & .944 \\
$40,001-60,000$ baht & 5.04 & - & - & - & .162 & .967 & .892 \\
$60,001-80,000$ baht & 5.66 & - & - & - & - & .970 & .996 \\
$80,001-100,000$ baht & 5.34 & - & - & - & - & - & 1.000 \\
$\geq 100,000$ baht & 5.45 & - & - & - & - & - & - \\
\hline
\end{tabular}

\subsection{The relationship between the Political Ideologies and the Prioritization of the Quality of Men to be Chosen as a Boyfriend}

The analysis of the relationship between the political ideology and the prioritization of the quality of men to be chosen as a boyfriend, by way of Pearson's correlation coefficient, finds that the two variables are only slightly inversely related, with the correlation coefficient being equal to -0.100 . When each aspect of the quality is considered, it is found that the political ideology has a weak, inverse relationship with the men's occupation (correlation coefficient $=-0.099)$ and their sexual skill (correlation coefficient $=-0.174)($ Table 14). 
Table 14. Relationship between ideology and prioritization of the quality of men to be chosen as a boyfriend

\begin{tabular}{llll}
\hline & Correlation coefficient & p-value & Relationship level \\
\cline { 2 - 3 } & Ideology & .099 & Very weak \\
\hline Family background & -.083 & .189 & Very weak \\
Age & -.066 & .115 & Very weak \\
Financial status & -.079 & $.048^{*}$ & Very weak \\
Occupation & -.099 & .386 & Very weak \\
Physical appearance & -.043 & .945 & Very weak \\
Personal character & -.003 & .603 & Very weak \\
Intellect & -.026 & .470 & Very weak \\
Social celebrity & -.036 & .269 & Very weak \\
Other possible benefits & -.055 & $.000^{* *}$ & Very weak \\
Sexual skill & -.174 & $\mathbf{. 0 4 7 *}$ & Very weak \\
\hline $\begin{array}{l}\text { Prioritization of the quality of men to be } \\
\text { chosen as a boyfriend }\end{array}$ & -.100 & & \\
\hline
\end{tabular}

\section{Conclusion and Discussion}

In conclusion, the sample used in this research on average leans slightly towards liberalism and gives a moderate priority to the quality of men to be chosen as a boyfriend. The personal characters and intellect are the two qualities to which Thai female students gives the top priorities. Unlike the hidden messages within our cultural codes or constantly communicated via various media, financial status, physical appearance, social celebrity, or other possible benefits are not the qualities to which top priorities are paid. Another especially interesting point is the finding that Thai female students rank sexual skills with greater priority than the men's family background, occupation, social celebrity or other possible benefits.

Furthermore, the Thai female students with various combinations of five personal factors, including class years, majors, hometowns, parent's occupation, and household incomes, all differently prioritize the quality of the boyfriend-to-be. When the factors are considered in greater details, it is first found that from the first year to the third year of the university, the female students give a continually lower priority to this matter. It is not until the fourth year when the female students begin to give a high priority to the matter again, at a level more than they do before. Second, the female students majoring in science and technology give a greater priority to the matter than do those majoring in humanities and social science. Third, the female students from the Northern and the Northeastern regions tend to give a higher priority to the quality of the boyfriend-to-be than do those who come from the Central region, Bangkok and its vicinities, and the Southern region. Fourth, the female students whose parent's occupation is relatively stable tend to give a lower priority to the matter than do those whose parent's occupation may be considered less stable. Fifth, the female students whose financial status is not as well-off tend to give a higher priority to the matter than do those with better financial status.

Three of five conclusions posited above point to the same direction. The hometowns, when taking into account the 2014 regional-level gross provincial product collected by the National Statistics Office (2015), the parent's occupation, the household income may together lead to a clearer conclusion, where the economic status or the economic stability has an inverse relationship with the priority level given by each woman on the quality of men she chooses to date. Specifically, the female students of less stable economic status tend to give a higher priority to this matter, while those with more stable economic status tend to give a lower priority to such matter.

Finally, the political ideology and the prioritization of the quality of the boyfriend-to-be among Thai female students is found to have a very weak inverse relationship. More specifically, the political ideology is also found to have a similar pattern of relationship with the man's occupation and his sexual skills. Not only do the results show that the more conservative-leaning a Thai female student is, the more priority she gives to the quality of her boyfriend-to-be, particularly with regards to the boyfriend's occupation and sexual skills, but the results confirm the idea of political psychologists with regards to the importance of political ideology and people's daily lives as well. 


\section{Competing Interests Statement}

The authors declare that there are no competing or potential conflicts of interest.

\section{References}

Aron, R. (1968). The End of the Ideological Age?. in C. Waxman (ed.). The End of Ideology Debate (pp. 27-48). New York: Simon \& Schuster.

Bell, D. (1960). The End of Ideology. Illinois: Free Press.

Boy. (2016). Five Qualities of Men that Women Want in a Boyfriend. Retrieved from www.boy.in.th.

Carney, D., Jost, J., Gosling, S. \& Potter, J. (2008). The Secret Lives of Liberals and Conservatives: Personality Profiles, Interaction Styles, and the Things They Leave Behind. Political Psychology, 29(6), 807-840. https://doi.org/10.1111/j.1467-9221.2008.00668.x

Cochran, W. (1977). Sampling Techniques (3rd ed.). New York: John Wiley \& Sons.

Converse, P. (1964). The Nature of Belief Systems in Mass Publics. In D. Apter (ed.), Ideology and Discontent (pp. 206-261). New York: Free Press.

Dara Daily. (2017). Reveal the List of 11 Handsome, Wealthy, High-society Men that Would Melt Women's Hearts. Retrieved from www.daradaily.com/news/59964/rea

Gerring, J. (1997). Ideology: A Definitional Analysis. Political Research Quarterly, 50(4), 957-994. https://doi.org/10.1177/106591299705000412

Graham, J., Haidt, J., \& Nosek, B. (2009). Liberals and Conservatives Rely on Different Sets of Moral Foundations. Journal of Personality and Social Psychology, 96(5), 1029-1046. https://doi.org/10.1037/a0015141

Hinkle, D., Wiersma, W., \& Jurs, S. (2003). Applied Statistics for the Behavioral Sciences (5th ed.). Massachusetts: Houghton Mifflin.

Jermsittiparsert, K., \& Theansri, W. (2017). Henpeckedness in Relationships of Students of a University of Thailand. Governance Journal, 6(1), 245-264.

Jost, J. (2006a). Revisiting the End of Ideology Claims: An Emerging Psychological Paradigm for the Study of Ideology. Psicología Política, (33), 75-100.

Jost, J. (2006b). The End of End of Ideology. American Psychologist, 6(7), 651-670. https://doi.org/10.1037/0003-066X.61.7.651

Jost, J., \& Amodio, D. (2012). Political Ideology as Motivated Social Cognition: Behavioral and Neuroscientific Evidence. Motivation and Emotion, 36, 55-64. https://doi.org/10.1007/s11031-011-9260-7

Jost, J., Glaser, J., Kruglanski, A., \& Sulloway, F. (2003). Political Conservatism as Motivated Social Cognition. Psychological Bulletin, 129(3), 339-375. https://doi.org/10.1037/0033-2909.129.3.339

Klofstad, C., McDermott, R., \& Hatemi, P. (2012). The Dating Preferences of Liberals and Conservatives. Political Behavior, 35(3), 519-538. https://doi.org/10.1007/s11109-012-9207-z

Lipset, S. 1960. Political Man. New York: Doubleday.

National Statistics Office. 2015. Average Income per Head by Region and Province, 2005-2014. Retrieved from service.nso.go.th/nso/web/statseries/tables/00000_Whole_King

Pantip. (2013). Handsome Men VS Wealthy Men. Retrieved from pantip.com/topic/3082079

Pantip. (2014). In Women's Eyes, What are the Qualities of Good Men?. Retrieved from pantip.com/topic/32303502.

Pantip. (2016). Why Women Choose Money Over Love?. Retrieved from pantip.com/topic/3

Shils, E. (1968). "The End of Ideology?." in C. Waxman (ed.). The End of Ideology Debate, 49-63. New York: Simon \& Schuster.

Wanthana, S. (2008). Contemporary Political Ideologies (2nd ed.). Bangkok: Political Science Association of Kasetsart University.

Wongnai. (2015). Women's 10 Single Dream Men. Retrieved from www.wongnai.com/articl

Young, E. (2009). Why We're Liberal, Why We're Conservative: A Cognitive Theory on the Origins of Ideological Thinking (Ph.D. in Political Science Dissertation, Stony Brook University). 


\section{Note}

Note 1. Computed by deducting the conservatism score from the liberalism score and classified into seven groups, including (1) highly liberal (average from 2.68 to 4.00), (2) liberal (average from 1.34 to 2.67), (3) mildly liberal (average $=$ from 0.01 to 1.33$),(4)$ moderate (average $=0),(5)$ mildly conservative (average from -0.01 to 1.33 ), (6) conservative (average from -1.34 to -2.67 ), and (7) highly conservative (average from -2.68 to $-4.0)$

\section{Copyrights}

Copyright for this article is retained by the author(s), with first publication rights granted to the journal.

This is an open-access article distributed under the terms and conditions of the Creative Commons Attribution license (http://creativecommons.org/licenses/by/4.0/). 